\title{
Gold magnetic nanoparticle conjugate-based lateral flow assay for the detection of IgM class antibodies related to TORCH infections
}

\author{
XINGXING LI ${ }^{1 *}$, QINLU ZHANG ${ }^{2,3 *}$, PENG HOU ${ }^{3}$, MINGWEI CHEN $^{3}$, WENLI HUI ${ }^{1}$, \\ ALPHONS VERMORKEN ${ }^{1,2}$, ZHIYI LUO ${ }^{1}, \mathrm{HONG} \mathrm{LI}^{4}, \mathrm{QIN} \mathrm{LI}^{4}$ and YALI CUI ${ }^{1,2}$ \\ ${ }^{1}$ College of Life Sciences, Northwest University; ${ }^{2}$ National Engineering Research Center for Miniaturized Detection Systems, \\ Xi'an, Shaanxi 710069; ${ }^{3}$ School of Medicine, The First Affiliated Hospital of Xi'an Jiaotong University, Xi'an, Shaanxi 710061; \\ ${ }^{4}$ The Second Affiliated Hospital of Shaanxi University of Chinese Medicine, Xianyang, Shaanxi 712000, P.R. China
}

Received April 18, 2015; Accepted July 21, 2015

DOI: $10.3892 /$ ijmm.2015.2333

\begin{abstract}
In this study, a lateral flow immunochromatographic assay (LFIA) system for the detection of immunoglobulin M (IgM) antibodies, related to TORCH [(T)oxoplasmosis, (O) ther agents, (R)ubella (also known as German Measles), (C) ytomegalovirus, and $(\mathrm{H})$ erpes simplex virus infections], based on gold magnetic nanoparticles, was established. Following modification with poly(methacrylic acid), the gold magnetic nanoparticles conjugated with an anti-human IgM antibody ( $\mu$-chain specific) to construct a probe. A lateral flow assay device was constructed based on these conjugates. IgM antibodies to four types of pathogens, notably toxoplasmosis, rubella virus, cytomegalovirus and herpes simplex virus type 2, were detected using this device. Compared with commercial colloidal gold-based LFIA strips, our method exhibited higher sensitivity. No interference with triglycerides, hemoglobin and bilirubin occurred, and no cross-reactivity was noted among the four pathogens. The gold magnetic nanoparticle-LFIA strips were used to assess 41 seropositive and 121 seronegative serum
\end{abstract}

Correspondence to: Professor Yali Cui, College of Life Sciences, Northwest University, 229 Taibai North Road, Xi'an, Shaanxi 710069, P.R. China

E-mail: yalicui@nwu.edu.cn

Professor Peng Hou, School of Medicine, The First Affiliated Hospital of Xi'an Jiaotong University, 277 Yanta West Road, Xi'an, Shaanxi 710061, P.R. China

E-mail: penghou@126.com

*Contributed equally

Abbreviations: PMAA, poly(methacrylic acid) sodium salt; BS, borate saline; EDC, 1-ethyl-3-(3-dimethylaminopropyl)carbodiimide hydrochloride; TOX, toxoplasmosis; RV, rubella virus; CMV, cytomegalovirus; HSV, herpes simplex virus; POCT, point-of-care testing; LFIA, lateral flow immunochromatographic assay; GoldMag,PMAAmodified gold magnetic nanoparticles

Key words: TORCH IgM antibody, lateral flow immunochromatographic assay, gold magnetic nanoparticles, poly(methacrylic acid), detection samples. The sensitivity was $100 \%(162 / 162)$ and the specificity was $100 \%(162 / 162)$. This method cannot only be used for the detection of TORCH IgM-specific antibodies, but it can potentially be developed for use in the diagnosis of other acute or recently identified autoimmune diseases.

\section{Introduction}

The acronym TORCH was proposed in 1971 by Nahmias et al (1) to denote 4 congenital infections which affect fetuses and newborns, namely (T)oxoplasmosis (TOX; caused by Toxoplasma gondii infection), (R)ubella virus (RV; also known as German Measles), (C)ytomegalovirus (CMV) and (H)erpes simplex virus (HSV) types 1 and 2 (HSV-1/2). These diseases are common causes of congenital infections which lead to a syndrome that includes one or more of the following clinical symptoms: low birth weight, prematurity, purpura, jaundice, anaemia, microcephaly, hydrocephaly, cerebral calcification, chorioretinitis, cataracts, microphthalmia and pneumonitis (2-6). As more infections that cause similar clinical symptoms became recognised, the ' $\mathrm{O}$ ' in the acronym came to stand for 'Other' pathogens.

TORCH infections now include under 'Other' pathogens, such as syphilis, parvovirus B19, enterovirus, hepatitis B and human immunodeficiency virus (HIV). Primary infections with TORCH pathogens, including those in pregnant women, are usually subclinical and, even if symptomatic, lack specificity in terms of their symptoms and signs $(7,8)$. Most importantly, the pathogens can be vertically transmitted to the fetus through the placenta after maternal primary infection. This may result in spontaneous abortion, prematurity and fetal or neonatal infections $(9,10)$. The World Health Organization (WHO) has estimated that $>100,000$ infants are born with congenital rubella syndrome (CRS) each year (11). Moreover, an association between infection with HIV and infection with TORCH pathogens has been demonstrated $(12,13)$. Existing strategies to protect against, or to treat TORCH infections during pregnancy are, thus far, limited (7). Therefore, the prevention and early diagnosis of TORCH infections is a matter of great importance for pregnant women (14).

Currently, the identification of primary TORCH infections in pregnant women is achieved by the detection of TORCH 
pathogen-specific immunoglobulin $\mathrm{G}$ (IgG) and/or immunoglobulin M (IgM) antibodies. Of these, TORCH-specific IgM antibodies have been shown to be an indicator of acute and recent TORCH pathogen infection, as the IgM antibody can be detected within 2 weeks of infection (15). IgM antibody can be detected by enzyme-linked immunosorbent assay (ELISA) with a relatively high level of specificity and sensitivity. However, the lack of adequate laboratory infrastructures and the time-consuming nature of the procedures constitute obstacles to the rapid detection and diagnosis.

Point-of-care testing (POCT) is now emerging as an excellent and effective method which can circumvent these above-mentioned issues (16-19). The substantial progress made in research on lateral-flow immunochromatographic assay (LFIA) and nanomaterials has contributed to their increasing application in the detection of proteins and pesticide residues and for the diagnosis of disease (20-25). In previous studies, a series of ligands, such as poly(acrylic acid) (PAA), poly-L-lysine and polystyrene were attached to the nanoparticles, and this markedly influenced particle behaviour and spatial distribution (26-28). This significantly impacted on the performance of the LFIA detection system.

TORCH-pathogens have been detected using various methods (29-32). In the present study, poly(methacrylic acid) (PMAA)-modified gold magnetic nanoparticles (GoldMag) were applied in the LFIA system for the simultaneous detection of 4 different TORCH pathogens, notably TOX, RV, CMV and HSV-2.

\section{Materials and methods}

Reagents and materials. Gold magnetic nanoparticles were purchased from Xi'an GoldMag Nanobiotech Co., Ltd. (Xi'an, China). Mouse anti-human $\operatorname{IgM}$ ( $\mu$-chain) monoclonal antibody was purchased from HyTest Ltd. (Turku, Finland). Toxoplasma antigen was purchased from Ruislip Biotech Ltd. (Hillingdon, UK). Purified rubella antigen, CMV-M concentrate antigen and HSV-2 antigen were obtained from Meridian Life Science, Inc. (Saco, ME, USA). Goat anti-mouse IgG serum was purchased from Solarbio Co., Ltd. (Beijing, China). Bovine serum albumin (BSA), triglyceride, hemoglobin and bilirubin were obtained from Sigma-Aldrich (St. Louis, MO, USA). All chemicals were of analytical-reagent grade and were used as received without further purification. Ultrapure water was used in the experiments.

Preparation of GoldMag and mouse anti-human IgM( $\mu$-chain) monoclonal antibody conjugation. GoldMag were prepared according to the method described in our previous study (24). As shown in Fig. 1, the mouse anti-human $\operatorname{IgM}$ ( $\mu$-chain) monoclonal antibody (anti-human $\operatorname{IgM}$ ) covalently bonded on the surface of GoldMag using 1-ethyl-3-(3-dimethylaminopropyl) carbodiimide (EDC) as a linker. The preparation of the conjugates was carried out as follows: firstly, $1 \mathrm{mg}$ of particles was equilibrated in $1 \mathrm{ml}$ of borate saline (BS) buffer $(0.02 \mathrm{M})$ in a tube, and $15 \mu \mathrm{l}$ of EDC $(5 \mathrm{mg} / \mathrm{ml})$ were added dropwise. The mixture was further processed by ultrasonication for $20 \mathrm{~min}$. Anti-human IgM antibody was added to the EDC-activated particles and incubated for $1 \mathrm{~h}$. Subsequently, the GoldMag anti-human IgM complex was separated magnetically and the supernatant (solution contained unbound anti-human $\operatorname{IgM}$ ) was removed. The conjugation efficiency was calculated by determining the concentration of anti-IgM antibody in the solution before and after coupling using the BCA protein assay method. Secondly, in order to cover the non-specific binding sites, the GoldMag anti-human IgM complex was further blocked with $3 \%(\mathrm{w} / \mathrm{v}) \mathrm{BSA}$ and $5 \%(\mathrm{v} / \mathrm{v})$ calf serum in BS buffer, and incubated for another $40 \mathrm{~min}$. After washing with BS buffer containing $0.05 \%$ (v/v) Tween-20, the GoldMag anti-human IgM complex was magnetically separated and finally suspended in $200 \mu \mathrm{l} \mathrm{BS}$ suspension buffer containing $1 \%$ (w/v) BSA. These functional gold magnetic nanoparticles were stored at $4^{\circ} \mathrm{C}$ and were ready to use.

LFIA device. The structure of the LFIA strip is illustrated in Fig. 2A. The 4x40-mm lateral flow immunochromatographic strip consists of 5 components, namely a sample pad, a conjugate pad, a nitrocellulose (NC) membrane, an absorbent pad and a plastic backing. Some elements were treated before the device was constructed. The sample pad was saturated with BS buffer containing $0.5 \%$ (v/v) rabbit anti-human IgG serum, and the conjugate pad was immersed in ultrapure water containing $0.2 \%$ (v/v) Triton X-100, 0.2\% (v/v) Tween-20 and 0.8\% (w/v) sucrose. Subsequently, a solution of $5 \mathrm{mg} / \mathrm{ml}$ of the GoldMag anti-human IgM conjugates, prepared as described above, was sprayed onto the conjugate pad using a Biodot AirJet dispensing apparatus (BioDot, Irvine, CA, USA). TORCH antigens and goat anti-mouse $\mathrm{IgG}(2 \mathrm{mg} / \mathrm{ml})$ were respectively sprayed on the NC membrane to form a test line (T-line) and a control line (C-line). Finally, the whole LFIA device was assembled after all the aforementioned components had dried fully.

A schematic diagram of the method for TORCH-IgM antibody detection is illustrated in Fig. 2B, and Fig. 2C depicts possible detection results. More specifically, $60 \mu \mathrm{l}$ of human sera, which possibly contained TORCH-IgM were dropped onto the sample pad. The solution migrated toward the absorbent pad via capillary force and rehydrated the GoldMag anti-human IgM conjugates. If the testing sera contained TORCH-IgM antibodies, the GoldMag anti-human IgM probes recognised and captured them. When the complexes reached the T-line, the immobilised TORCH antigens interacted with the captured TORCH-IgM antibodies, and when they reached the C-line, the immobilised goat anti mouse IgG antibody (anti-mouse $\mathrm{IgG}$ ) captured the excess GoldMag anti-human IgM probes. Thus, 2 characteristic red bands were observed within 15 min. However, healthy sera without a TORCH-IgM antibody led to a red band on the $\mathrm{C}$-line.

Evaluation of the TORCH-LFIA system. The sensitivity, repeatability, reproducibility and specificity of the TORCH-LFIA system were evaluated (negative sera were used as controls in all experiments). First, $60 \mu 1$ standard TORCH-IgM positive control sera purchased from SeraCare Life Sciences, Inc. (Milford, MA, USA) were used to test the sensitivity of the system. The repeatability was then investigated by testing the same TORCH samples $(60 \mu \mathrm{l}) 10$ times with the same batch of GoldMag-based test strips (the concentrations of TOX IgM, RV IgM, CMV IgM and HSV IgM were 13.7, 42.5, $32 \mathrm{Au} / \mathrm{ml}$ and $2.93 \mathrm{~S} / \mathrm{CO}$, respectively). The reproducibility was determined by testing the same TORCH samples with 3 batches 


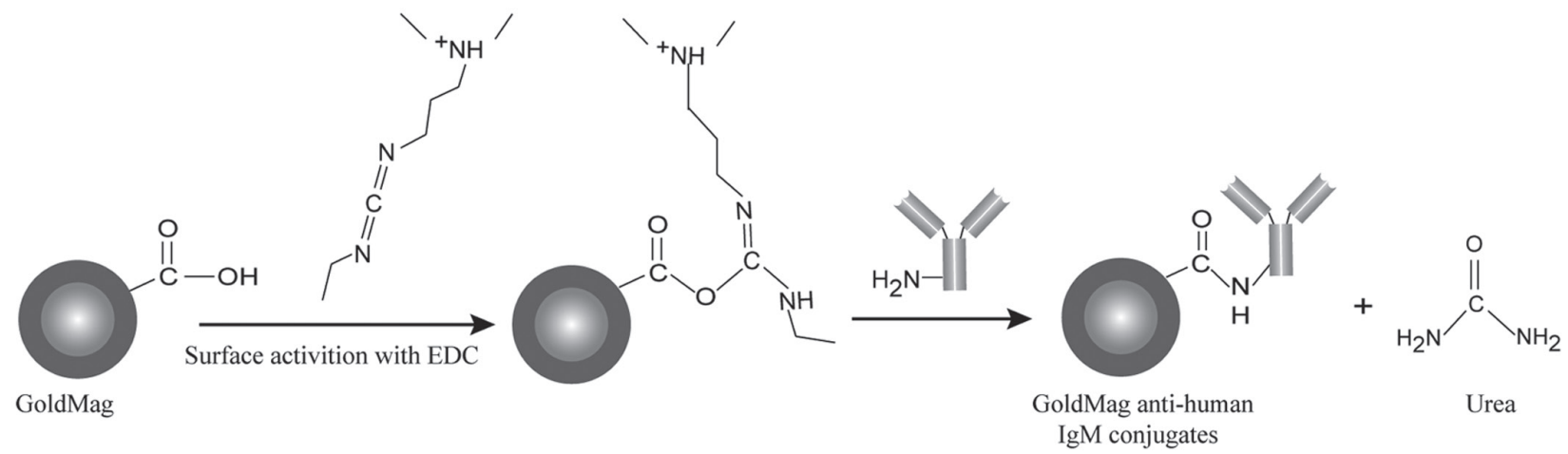

Figure 1. Coupling procedure for mouse anti-human immunoglobulin M (IgM) monoclonal antibody on the surface of poly(methacrylic acid) (PMAA)-modified gold magnetic nanoparticles (GoldMag), using 1-ethyl-3-(3-dimethylaminopropyl)carbodiimide hydrochloride (EDC) as a linker.

A Sample pad Conjugate pad Test line Control line Absorbent pad

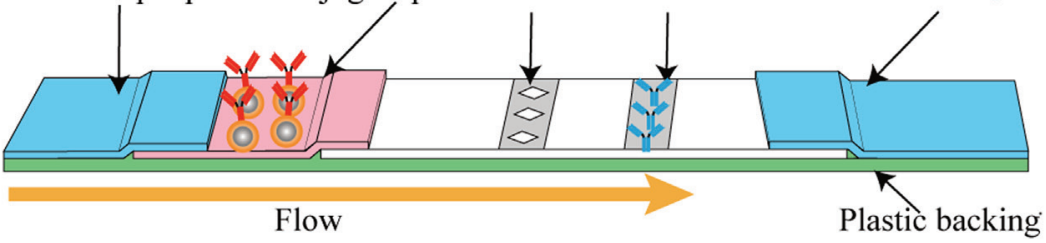

B
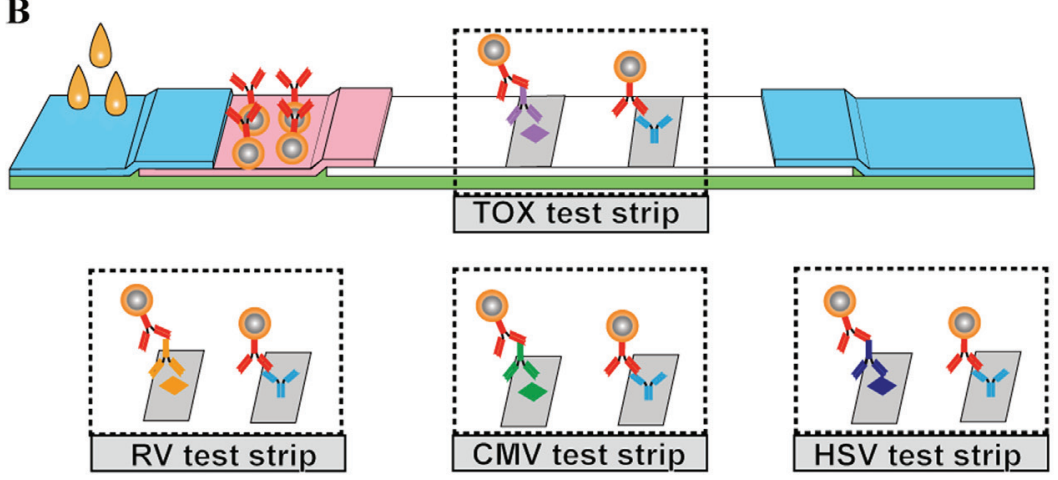

C

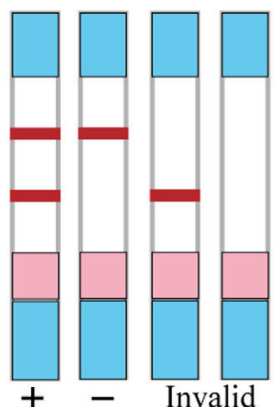

Yै: GoldMag Anti-human IgM conjugates

$Y:$ TOX IgM antibody $\quad \bullet$ : TOX antigen

$Y:$ RV IgM antibody $\quad \rightarrow:$ RV antigen

$Y:$ : MV IgM antibody

$\bullet:$ CMV antigen

$Y:$ HSV IgM antibody

$\bullet:$ HSV antigen

Y : anti-mouse IgG

(1) Analyte

Figure 2. (A) Schematic representation of the structure of the lateral flow immunochromatographic assay (LFIA) strip. (B) Schematic diagram of the TORCH-IgM antibody detection method. (C) Illustration of possible detection results. GoldMag, poly(methacrylic acid) (PMAA)-modified gold magnetic nanoparticles; TOX, toxoplasmosis; RV, rubella virus; CMV, cytomegalovirus; HSV, herpes simplex virus.

of GoldMag-based test strips. For interference testing, one sample of TORCH-negative and one of TORCH-positive serum were split and individually spiked with $33 \mathrm{mg} / \mathrm{ml}$ triglycerides, $0.2 \mathrm{mg} / \mathrm{ml}$ bilirubin and $5 \mathrm{mg} / \mathrm{ml}$ hemoglobin samples (the concentrations of TOX, RV, CMV, HSV IgM were 13.7, 44, $49.7 \mathrm{Au} / \mathrm{ml}$ and 3.5 S/CO, respectively). The results from $60 \mu \mathrm{l}$ spiked samples were compared with those from
$60 \mu \mathrm{l}$ non-spiked serum samples. For cross-reactivity assays, $60 \mu \mathrm{l}$ TOX-positive serum (the concentration of TOX IgM was 25.3 Au/ml), RV-positive serum (the concentration of RV IgM was $76.1 \mathrm{Au} / \mathrm{ml}$ ), CMV-positive serum (the concentration of CMV IgM was $76.1 \mathrm{Au} / \mathrm{ml}$ ) and $\mathrm{HSV}-2$ positive serum (the concentration of HSV IgM was $2.67 \mathrm{~S} / \mathrm{CO}$ ) were assessed (these 4 serum samples contained only one specific TORCH 
pathogen each as opposed to 2 or more TORCH pathogens). All results were presented in the form of optical images, which were captured using a digital camera D7000 (Nikon, Tokyo, Japan).

Detection of human serum samples with TORCH-LFIA strips. Human serum samples which were positive for TOX $(n=3)$, CMV ( $n=14), H S V-2(n=19)$ and RV $(n=5)$ were obtained from Xiangya Hospital (Changsha, China). Negative serum samples $(n=121)$ were collected from The Second Affiliated Hospital of Shaanxi University of Chinese Medicine (Shaanxi, China). They were then re-tested using our LFIA strips. This study was approved by the Ethics Committee of the National Engineering Research Center for Miniaturized Detection Systems, Xi'an, China.

\section{Results}

Conjugation of GoldMag with targeted moieties. GoldMag particles were conjugated to anti-human $\operatorname{IgM}$ antibody in order to construct probes for the detection of TORCH-IgM antibodies. Dynamic light scattering was used to monitor the distribution of the hydrodynamic size of the gold magnetic nanoparticles before and after conjugation with anti-human IgM antibody. As shown in Fig. 3A, the hydrodynamic size of the antibody-conjugated particles, as compared to the corresponding GoldMag, was increased by approximately $18 \mathrm{~nm}$ (from $64.8 \pm 0.73$ to $82.7 \pm 0.34 \mathrm{~nm}$ ). The reasonable increment of the hydrodynamic size after the conjugation suggests that the antibody molecules were effectively coupled to the particles (33). This conclusion was further confirmed by UV visible spectroscopy. The characteristic absorption peak of the GoldMag was $532 \pm 0.53 \mathrm{~nm}$ (Fig. 3B). It shifted slightly to $536 \pm 0.61 \mathrm{~nm}$ when the anti-human IgM antibody was conjugated to the GoldMag, which indicates that the surface chemical structure of the GoldMag changed from one with a non-antibody layer to that with an antibody layer, as previously described (34).

To achieve optimal performance, experimental parameters involved in the preparation of the GoldMag anti-human IgM conjugates were systematically optimised, including the $\mathrm{pH}$ value of the coupling buffer and the amount of anti-human IgM antibody added. Fig. 4A illustrates the determination of the optimum $\mathrm{pH}$ value of the coupling buffer. The amount of conjugate formed by GoldMag and anti-human IgM was higher under neutral conditions than under alkaline conditions. The addition of a coupling solution at $\mathrm{pH} 7.0$ resulted in the highest conjugation efficiency. Therefore, $\mathrm{pH} 7.0$ was selected as the optimal $\mathrm{pH}$ for the preparation of the GoldMag anti-human IgM conjugates.

To effectively utilise the antibody, the amount of anti-human IgM antibody added to $1 \mathrm{mg}$ of GoldMag was optimised. Fig. 4B demonstrates that increasing the amount of anti-human IgM led to a gradual increase in the amount of antibody conjugated to the GoldMag. However, when the amount of anti-human IgM reached $150 \mu \mathrm{g}$, the addition of more anti-human IgM antibody no longer increased the quantity of the conjugate. This indicated that the saturation of anti-human $\operatorname{IgM}$ antibody to the GoldMag was reached when the amount of conjugated antibody was approximately $94 \mu \mathrm{g}$. Therefore, the optimum amount of anti-human IgM antibody added was $150 \mu \mathrm{g}$ for $1 \mathrm{mg}$ GoldMag.
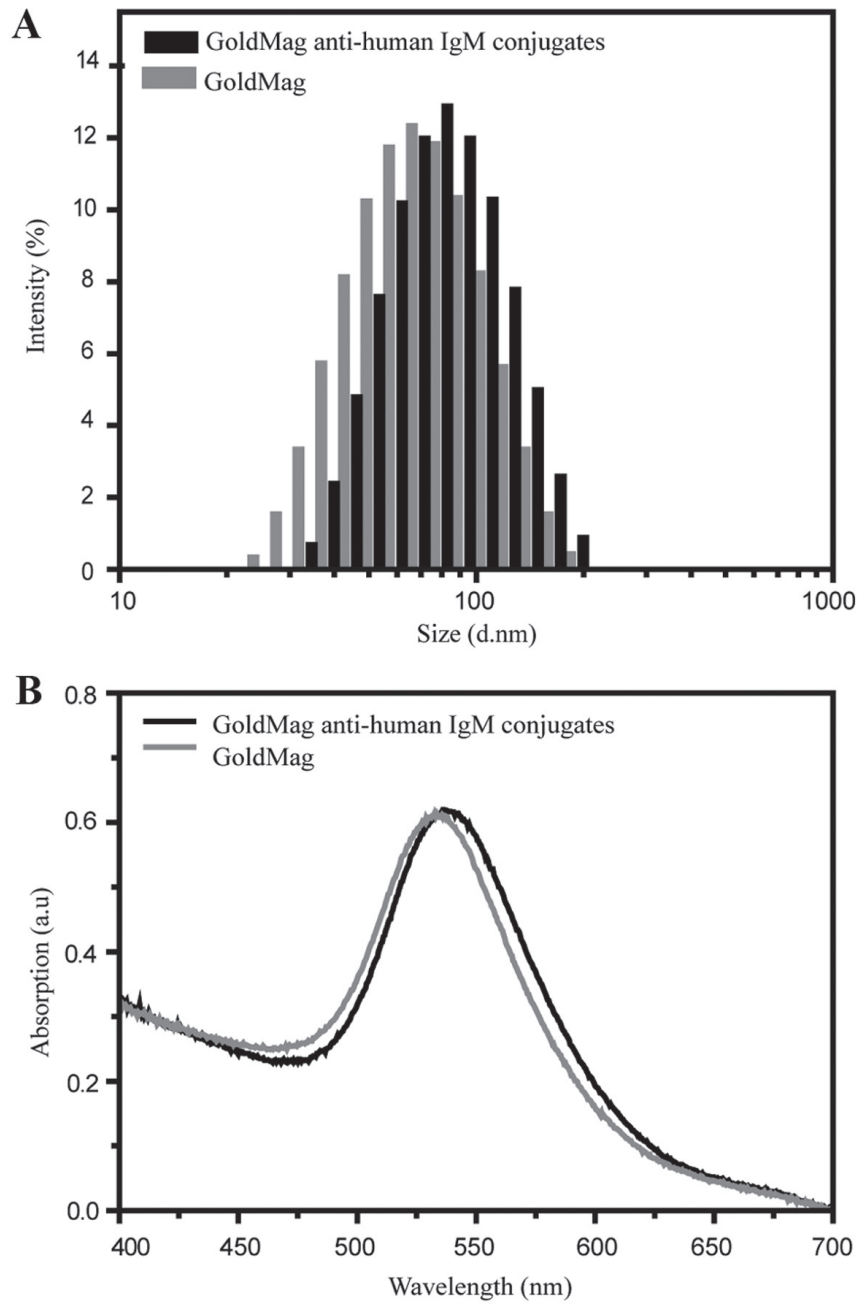

Figure 3. (A) Size distribution of poly(methacrylic acid) (PMAA)-modified gold magnetic nanoparticles (GoldMag) and GoldMag anti-human immunoglobulin $\mathrm{M}(\operatorname{Ig} \mathrm{M})$ conjugates monitored by a DLS analyser. (B) The UV-vis spectra of GoldMag and GoldMag anti-human IgM conjugates.

Sensitivity of TORCH IgM LFIA test strips. A standard TORCH-IgM positive control serum sample was used to compare the sensitivity of the GoldMag-based LFIA to a commercial colloidal gold-based immunoassay for the detection of TORCH IgM antibodies. Fig. 5 demonstrates that the GoldMag-based TORCH LFIA had a higher sensitivity than the colloidal gold-based LFIA.

Repeatability and reproducibility of measurements with the TORCH IgM LFIA test strips. The repeatability and reproducibility of the GoldMag-LFIA system were investigated. The colour intensity of the T-line on the test strips remained constant for all 4 pathogens: TOX, RV, CMV and HSV (Fig. 6). This indicates that within each batch of the GoldMag-LFIA system, the results are perfectly repeatable. Furthermore, Fig. 7 shows that the colour intensity of the T-lines of 3 different batches of the GoldMag-based test strips was constant, which confirms a high level of reproducibility of the LFIA.

Specificity of TORCH IgM LFIA test strips. Detecting whether a patient suffers from an infection with one pathogen or from an infection with multiple TORCH pathogens is of great signifi- 

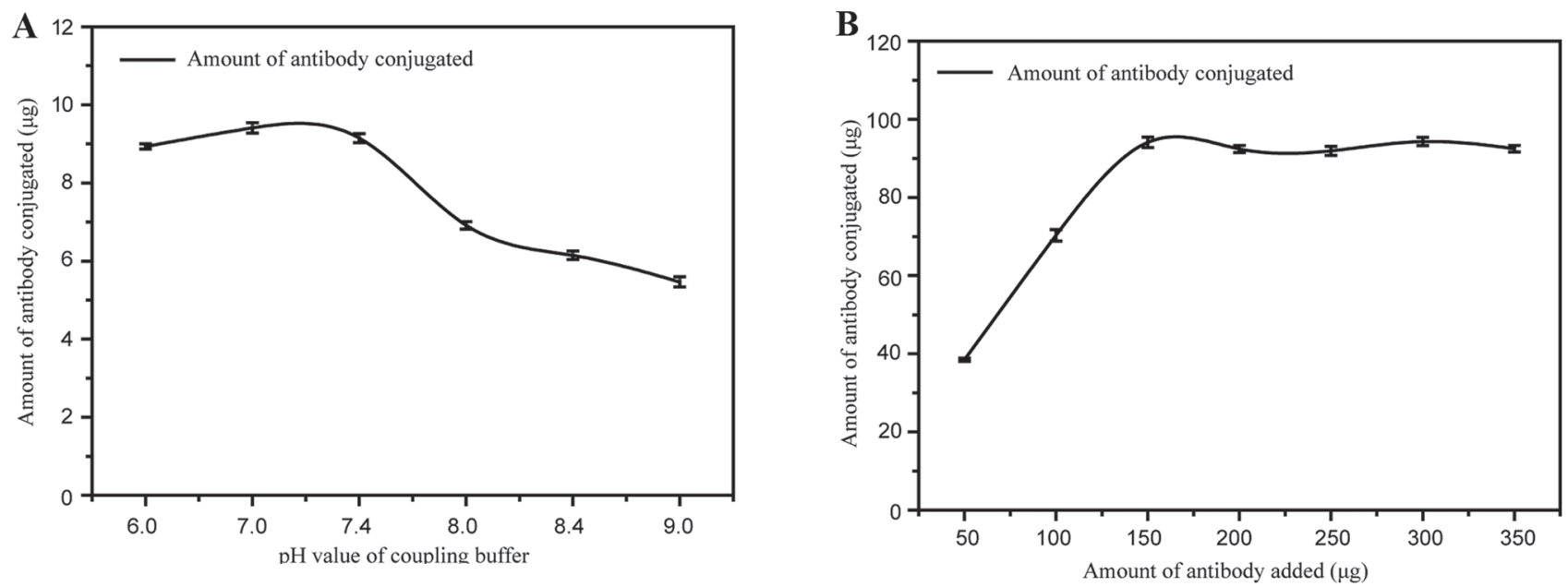

Figure 4. (A) Determination of the optimum pH value of the coupling buffer. (B) Determination of the amount of anti-human immunoglobulin M (IgM) needed to obtain optimal conjugation of $1 \mathrm{mg}$ of poly(methacrylic acid) (PMAA)-modified gold magnetic nanoparticles (GoldMag).

A

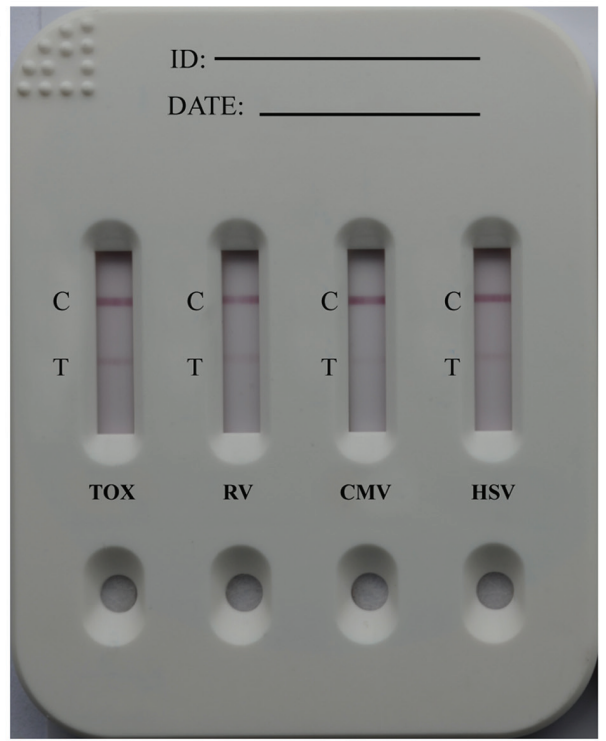

B

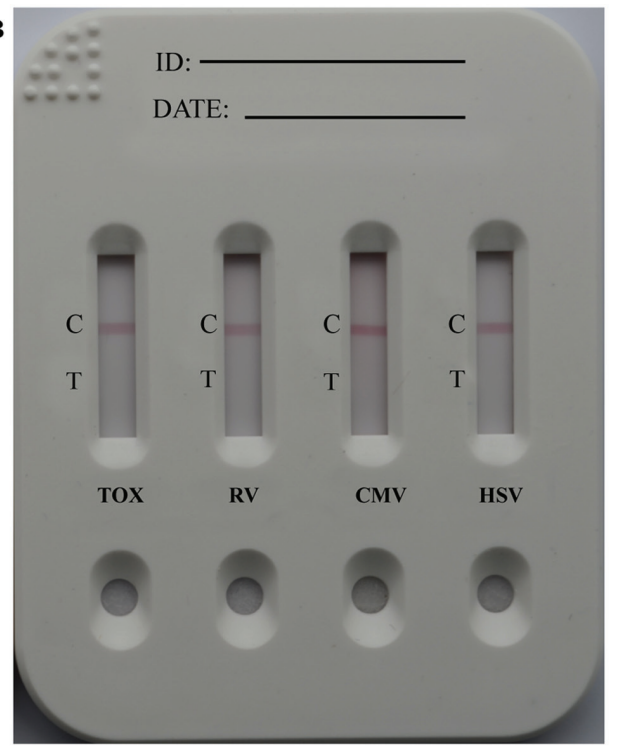

Figure 5. (A) Results of the tests of TORCH IgM class antibody detection using a poly(methacrylic acid) (PMAA)-modified gold magnetic nanoparticles (GoldMag)-lateral flow immunochromatographic assay (LFIA). (B) TORCH IgM class antibody detection using a commercial colloidal gold-based LFIA. TOX, toxoplasmosis; RV, rubella virus; CMV, cytomegalovirus; HSV, herpes simplex virus.

cance for accurate diagnosis, as it permits us to take appropriate therapeutic measures. It has been shown that different TORCH pathogens have a number of common antigenic determinants (33). If cross-reactivity occurs during the diagnostic determination, it leads to non-specific signals at the T-line, and thus to false-positive results. This has a negative impact on the diagnosis, and thus on the treatment of a TORCH infectious disease. It is therefore essential for each serum analysis to use a conjugate that captures only the specific antigen. This antigen is immobilised on the T-line of the 4 LFIA strips. In our study, to investigate the existence of possible cross reactivity, 4 serum samples, each containing antigens of one specific TORCH pathogen only, were respectively titrated to the sample pad of the same type of LFIA detection device (negative sera samples were used as controls). A particular test strip detected only the corresponding sample (Fig. 8). Other sera produced no observable binding at the T-line, indicating that each assay was specific for its own pathogen. Cross-reactivity between the assays did not occur.

It is also essential to assess whether common and potentially interfering substances in the sample have an impact on the test results. Therefore, TORCH IgM-negative and -positive serum samples, spiked with a number of potentially interfering substances, were added to the sample pad of the devices (untreated TORCH IgM-negative and -positive sera samples were used as controls). Sufficiently high concentrations of the interfering substances were spiked with the serum samples [triglycerides $(33 \mathrm{mg} / \mathrm{ml})$, bilirubin $(0.2 \mathrm{mg} / \mathrm{ml})$ and hemoglobin $(5 \mathrm{~g} / \mathrm{l})]$ in an attempt to elicit a response in the test zone of the corresponding assay. The results of the interference experiments are illustrated in Fig. 9. The TORCH IgM negative serum samples, whether control or spiked with potentially interfering 
A TOX test strip

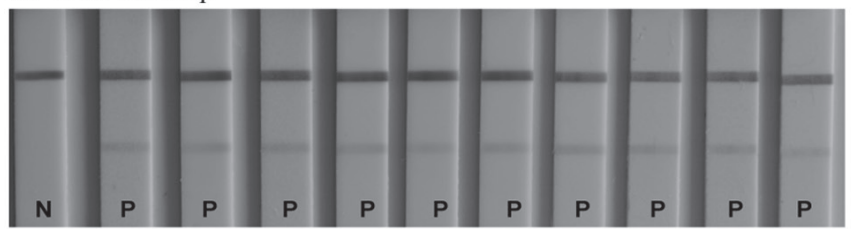

C CMV test strip

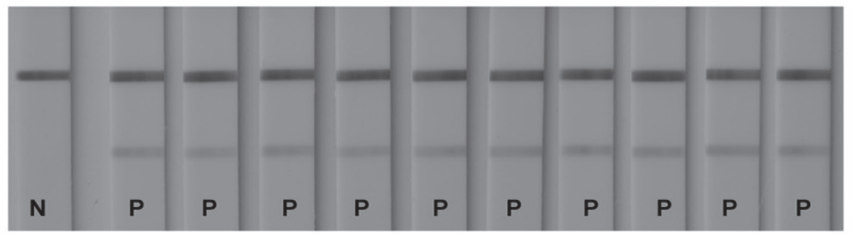

B RV test strip

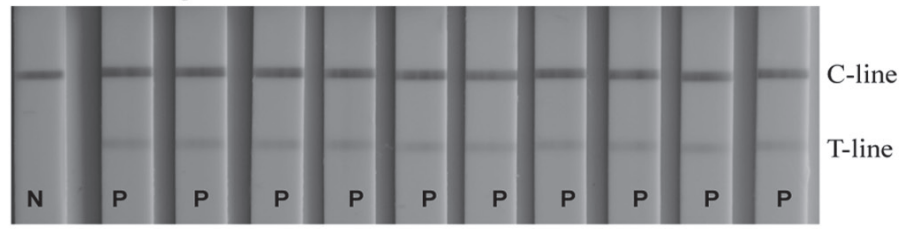

D HSV test strip

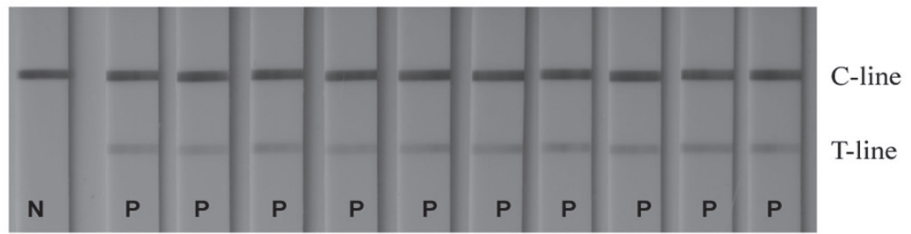

Figure 6. Results showing the repeatability of the tests with the poly(methacrylic acid) (PMAA)-modified gold magnetic nanoparticles (GoldMag)-lateral flow immunochromatographic assay (LFIA) strips. Results with (A) Toxoplasmosis (TOX) test strips. (B) Rubella virus (RV) test strips. (C) Cytomegalovirus (CMV) test strips. (D) Herpes simplex virus (HSV) test strips. C-line, control line; T-line, test line; N, negative serum; P, positive serum.

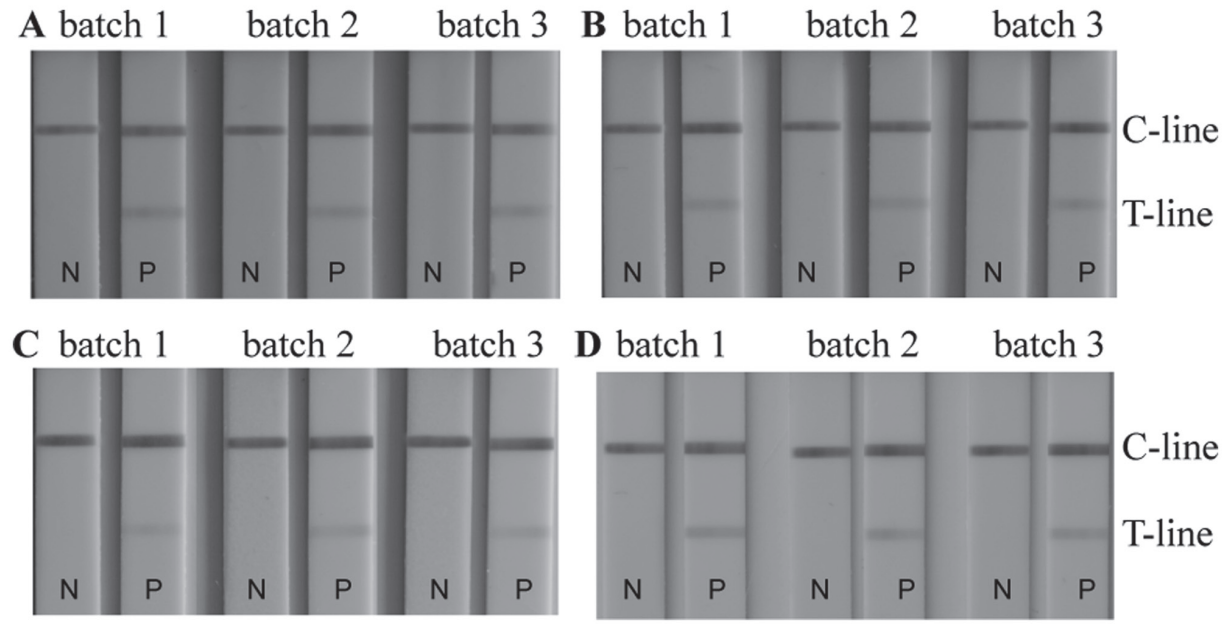

Figure 7. Evaluation of the intra-assay variation of 3 different batches of poly (methacrylic acid) (PMAA)-modified gold magnetic nanoparticles (GoldMag)-based TORCH test strips. (A) Toxoplasmosis (TOX) test strips. (B) Rubella virus (RV) test strips. (C) Cytomegalovirus (CMV) test strips. (D) Herpes simplex virus (HSV) test strips. C-line, control line; T-line, test line; N, negative serum; $\mathrm{P}$, positive serum.

A TOX test strip

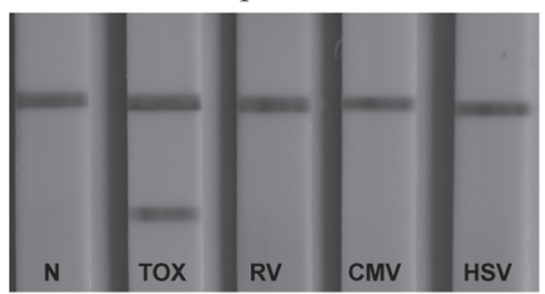

C CMV test strip

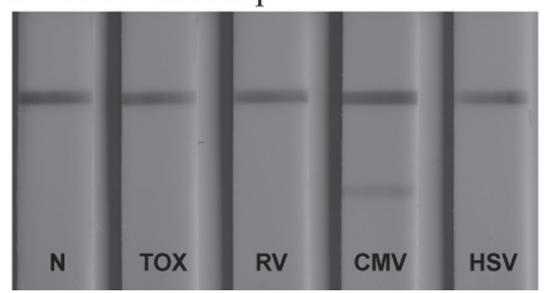

B RV test strip

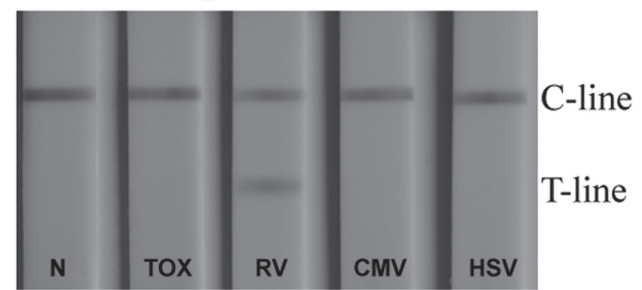

D HSV test strip

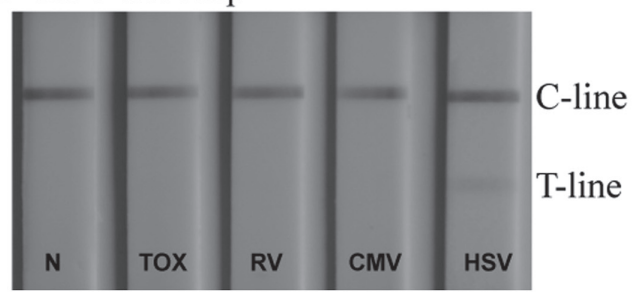

Figure 8. Investigation of possible cross-reactivity of the TORCH test strips. (A) Toxoplasmosis (TOX)-positive serum test strips. (B) Rubella virus (RV)-positive serum test strips. (C) Cytomegalovirus (CMV)-positive serum test strips. (D) Herpes simplex virus (HSV)-positive serum test strips. N, negative serum; C-line, control line; T-line, test line. 
A TOX test strip

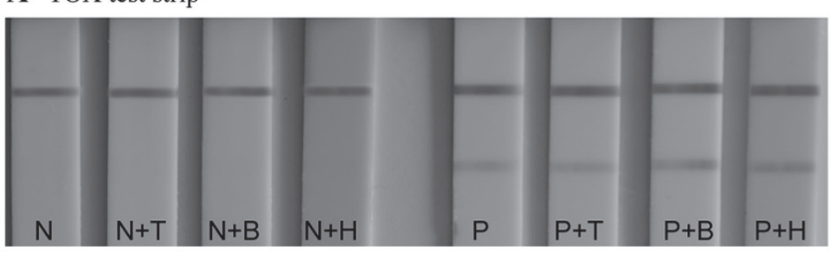

C CMV test strip

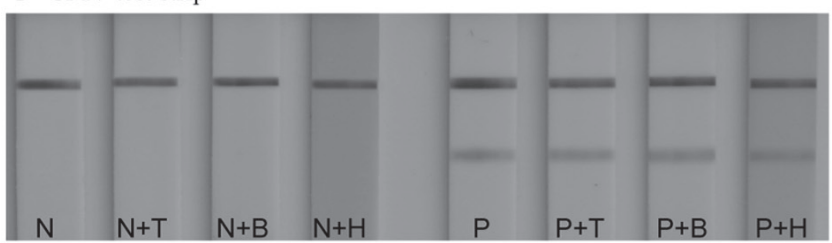

B RV test strip

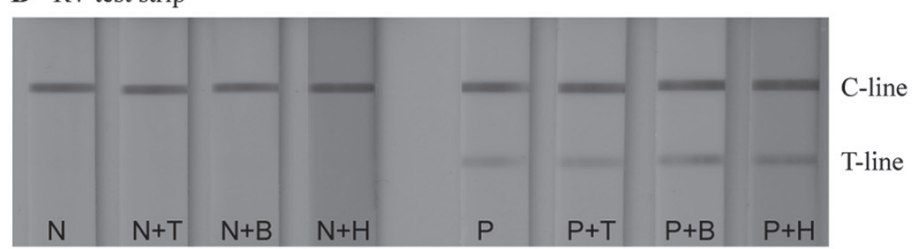

D HSV test strip

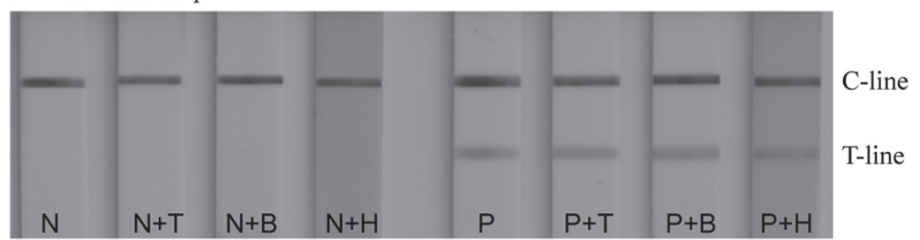

Figure 9. Evaluation of the possible effects of potentially interfering substances on the test results: (A) interference test on Toxoplasmosis (TOX) strips. (B) Interference test on rubella virus (RV) strips. (C) Interference test on cytomegalovirus (CMV) strips. (D) Interference test on herpes simplex virus (HSV) strips. $\mathrm{N}$, negative serum; $\mathrm{N}+\mathrm{T}$, negative serum with $33 \mathrm{mg} / \mathrm{ml}$ triglyceride; $\mathrm{N}+\mathrm{B}$, negative serum with $0.2 \mathrm{mg} / \mathrm{ml}$ bilirubin; $\mathrm{N}+\mathrm{H}$, negative serum with $5 \mathrm{~g} / \mathrm{l}$ hemoglobin; $\mathrm{P}$, positive serum; $\mathrm{P}+\mathrm{T}$, positive serum with $33 \mathrm{mg} / \mathrm{ml}$ triglyceride; $\mathrm{P}+\mathrm{B}$, positive serum with $0.2 \mathrm{mg} / \mathrm{ml}$ bilirubin; $\mathrm{P}+\mathrm{H}$, positive serum with $5 \mathrm{~g} / \mathrm{l}$ hemoglobin; C-line, control line; T-line, test line.

substances, demonstrated no non-specific reaction in any of the assays (the test zones remained colourless). Similarly, the TORCH IgM positive serum samples, whether control or spiked with potentially interfering substances exhibited the same colour intensity in the test zones. These results indicate that no interference occured on the TORCH LFIA test strips.

Detection of human sera samples with TORCH LFIA strips. Using GoldMag-based TORCH LFIA devices, 3 TOX, $5 \mathrm{RV}, 14 \mathrm{CMV}$ and $19 \mathrm{HSV}-2$ seropositive samples obtained from Xiangya Hospital and 121 negative sera samples were re-examined. The results indicated $100 \%$ specificity and $100 \%$ sensitivity. This demonstrates that the GoldMag-based immunoassay has great potential for use in the clinical diagnosis of human serum samples, and the results are considered highly accurate and reliable.

\section{Discussion}

The TORCH pathogens, including TOX, RV, CMV and HSV pose a serious threat to pregnant women and their fetuses. Unfortunately, existing strategies used to protect against, or to treat, TORCH infections during pregnancy are, thus far, limited (7). Therefore, a rapid and simple method for the early diagnosis of TORCH infections would allow for the better management of TORCH-infected diseases.

POCT has attracted considerable interest due to the fact that it is a rapid, time-saving and cost-effective menthod. In this study, a LFIA system was established using GoldMag nanoparticles instead of colloidal gold nanoparticles, which are widely used in conventional LFIAs. The gold magnetic nanoparticles modified by PMAA have carboxyl groups on their surfaces, and they covalently link with amino groups on the mouse anti-human IgM ( $\mu$-chain) monoclonal antibody after the carboxyl moieties have been activated by EDC. The procedure is a chemical coupling process, and the conjugated gold magnetic nanoparticles and antibodies are hardly influenced by physical effects. Moreover, the carboxyl moieties provide a more steric, ion-independent stabilization, and a hydrophilic surface layer for downstream applications (26). Compared with commercial colloidal gold-based LFIA strips, the PMAA-modified gold magnetic nanoparticle-based LFIA strips exhibited higher sensitivity. Moreover, no interference with triglycerides, hemoglobin or bilirubin was observed, and no cross-reactivity was noted among the 4 pathogens, suggesting that these strips have a high specificity for the IgM antibody of each of the TORCH pathogens examined.

The experimental parameters involved in the preparation of the GoldMag anti-human IgM conjugates, such as the $\mathrm{pH}$ value of the coupling buffer and the amount of antibody added, influenced the conjugation efficiency of the antibody and the stability of the conjugates. The conjugation efficiency of the antibody was highest when the $\mathrm{pH}$ of the coupling solution was 7.0 (Fig. 4A). This result is attributable to the charge of the anti-human $\operatorname{IgM}$ at different $\mathrm{pH}$ values. The saturation of anti-human $\operatorname{IgM}$ antiobdy to GoldMag was reached when $150 \mu \mathrm{g}$ of anti-human IgM was added (Fig. 4B). Adding greater quantities of anti-human IgM antibody did not lead to a significant difference in the quantity of anti-human $\operatorname{IgM}$ conjugated. This effect is related to the additional adsorption of antibodies and the occurrence of steric hindrance when there is a high density of antibodies on the nanoparticle surface $(35,36)$.

In conclusion, in this study, we successfully developed a gold magnetic nanoparticle conjugate-based lateral flow assay for the detection of TORCH IgM antibodies with high levels of sensitivity and specificity. The results imply that this method is sufficiently sensitive to detect TORCH antibodies in clinical samples. Additionally, the 4 test strips were assembled in plastic cases, thus making the detection method more convenient than others currently in use. Our GoldMag anti-human IgM conjugates can be applied for the detection of 4 different pathogens, as they were able to capture any IgM antibody that appeared in an immune response. The LFIA system that we established can therefore be further developed for utilization in the detection of other IgM-specific antibodies, including those for recently identified autoimmune diseases. Our TORCH LFIA method has great 
potential for future use in the simultaneous detection of several pathogens on a single LFIA device. This could be accomplished by spraying several pathogen antigens onto the NC membrane to form several T-lines. Efforts to establish a TORCH LFIA device capable of simultaneously determining the 4 TORCH pathogens, TOX, RV, CMV and HSV, are currently underway.

\section{Acknowledgements}

This study was supported by the Project of Prevention and Treatment of Major Infectious Diseases (no. 2013ZX10004804008) and the National Natural Science Foundation of China (no. 31200749).

\section{References}

1. Nahmias AJ, Walls KW, Stewart JA, Herrmann KL and Flynt WJ: The ToRCH complex-perinatal infections associated with toxoplasma and rubella, cytomegol- and herpes simplex viruses. Pediatr Res 5: 405-406, 1971.

2. Stegmann BJ and Carey JC: TORCH Infections. Toxoplasmosis, Other (syphilis, varicella-zoster, parvovirus B19), Rubella, Cytomegalovirus (CMV), and Herpes infections. Curr Womens Health Rep 2: 253-258, 2002.

3. Newton ER: Diagnosis of perinatal TORCH infections. Clin Obstet Gynecol 42: 59-70, 1999.

4. Adams Waldorf KM and McAdams RM: Influence of infection during pregnancy on fetal development. Reproduction 146: R151-R162, 2013.

5. Xu F, Sternberg MR, Kottiri BJ, McQuillan GM, Lee FK, Nahmias AJ, Berman SM and Markowitz LE: Trends in herpes simplex virus type 1 and type 2 seroprevalence in the United States. JAMA 296: 964-973, 2006.

6. Nigro G, Adler SP, La Torre R and Best AM; Congenital Cytomegalovirus Collaborating Group: Passive immunization during pregnancy for congenital cytomegalovirus infection. N Engl J Med 353: 1350-1362, 2005.

7. Delorme-Axford E, Sadovsky Y and Coyne CB: The placenta as a barrier to viral infections. Annu Rev Virol 1: 133-146, 2014.

8. Corey L and Wald A: Maternal and neonatal herpes simplex virus infections. N Engl J Med 361: 1376-1385, 2009.

9. Brown ZA, Selke S, Zeh J, Kopelman J, Maslow A, Ashley RL, Watts DH, Berry S, Herd M and Corey L: The acquisition of herpes simplex virus during pregnancy. N Engl J Med 337: 509-515, 1997.

10. Soper DE: Congenital cytomegalovirus infection: An obstetrician's point of view. Clin Infect Dis 57 (Suppl 4): S171-S173, 2013

11. De Santis M, Cavaliere AF, Straface G and Caruso A: Rubella infection in pregnancy. Reprod Toxicol 21: 390-398, 2006.

12. Mwaanza N, Chilukutu L, Tembo J, Kabwe M, Musonda K, Kapasa M, Chabala C, Sinyangwe S, Mwaba P, Zumla A and Bates M: High rates of congenital cytomegalovirus infection linked with maternal HIV infection among neonatal admissions at a large referral center in sub-Saharan Africa. Clin Infect Dis 58: 728-735, 2014.

13. Celum C, Wald A, Lingappa JR, Magaret AS, Wang RS, Mugo N, Mujugira A, Baeten JM, Mullins JI, Hughes JP, et al; Partners in Prevention HSV/HIV Transmission Study Team: Acyclovir and transmission of HIV-1 from persons infected with HIV-1 and HSV-2. N Engl J Med 362: 427-439, 2010.

14. Wallon M, Peyron F, Cornu C, Vinault S, Abrahamowicz M, Kopp CB and Binquet C: Congenital toxoplasma infection: Monthly prenatal screening decreases transmission rate and improves clinical outcome at age 3 years. Clin Infect Dis 56: 1223-1231, 2013.

15. Rorman E, Zamir CS, Rilkis I and Ben-David H: Congenital toxoplasmosis - prenatal aspects of Toxoplasma gondii infection. Reprod Toxicol 21: 458-472, 2006.

16. Niemz A, Ferguson TM and Boyle DS: Point-of-care nucleic acid testing for infectious diseases. Trends Biotechnol 29: 240-250, 2011.

17. Chan CP, Mak WC, Cheung KY, Sin KK, Yu CM, Rainer TH and Renneberg R: Evidence-based point-of-care diagnostics: Current status and emerging technologies. Annu Rev Anal Chem (Palo Alto, Calif) 6: 191-211, 2013.
18. Akanda MR, Joung HA, Tamilavan V, Park S, Kim S, Hyun MH, Kim MG and Yang H: An interference-free and rapid electrochemical lateral-flow immunoassay for one-step ultrasensitive detection with serum. Analyst (Lond) 139: 1420-1425, 2014.

19. Pöhlmann C, Dieser I and Sprinzl M: A lateral flow assay for identification of Escherichia coli by ribosomal RNA hybridisation. Analyst (Lond) 139: 1063-1071, 2014.

20. Xu H, Mao X, Zeng Q, Wang S, Kawde AN and Liu G: Aptamerfunctionalized gold nanoparticles as probes in a dry-reagent strip biosensor for protein analysis. Anal Chem 81: 669-675, 2009.

21. Xia X, Xu Y, Zhao X and Li Q: Lateral flow immunoassay using europium chelate-loaded silica nanoparticles as labels. Clin Chem 55: 179-182, 2009.

22. Kobys VL, Konovalenko VF, Repina NV, Golovko TS, Gulak LO, Tarasova TO, Zaharycheva EV and Matyushok OF: Treatment of large osteosarcoma in children: new approach. Exp Oncol 35: 105-108, 2013.

23. Song C, Liu Q, Zhi A, Yang J, Zhi Y, Li Q, Hu X, Deng R, Casas J, Tang L and Zhang G: Development of a lateral flow colloidal gold immunoassay strip for the rapid detection of olaquindox residues. J Agric Food Chem 59: 9319-9326, 2011.

24. Elingarami S, Deng Y, Fan J, Zhang Y and He N: NEIL-2 single nucleotide polymorphism genotyping using single base extension on core-shell $\mathrm{Fe}_{3} \mathrm{O}_{4} @ \mathrm{SiO}_{2} @$ Au magnetic nanoparticles and Association of the Genotypes with Gastric Cancer Risk in Northern Jiangsu (China). Sci Adv Mater 6: 899-907, 2014.

25. Jiang H, Zeng X, He N, Deng Y, Lu G and Li K: Preparation and biomedical applications of gold-coated magnetic nanocomposites. J Nanosci Nanotechnol 13: 1617-1626, 2013.

26. Yang D, Ma J, Zhang Q, Li N, Yang J, Raju PA, Peng M, Luo Y, Hui W, Chen C and Cui Y: Polyelectrolyte-coated gold magnetic nanoparticles for immunoassay development: Toward point of care diagnostics for syphilis screening. Anal Chem 85: 6688-6695, 2013.

27. Lee JY, Zhang Q, Emrick T and Crosby AJ: Nanoparticle Alignment and Repulsion during Failure of Glassy Polymer Nanocomposites. Macromolecules 39: 7392-7396, 2006.

28. Liu C, Jia Q, Yang C, Qiao R, Jing L, Wang L, Xu C and Gao M: Lateral flow immunochromatographic assay for sensitive pesticide detection by using $\mathrm{Fe}_{3} \mathrm{O}_{4}$ nanoparticle aggregates as color reagents. Anal Chem 83: 6778-6784, 2011.

29. Reiter-Owona I, Petersen E, Joynson D, Aspöck H, Dardé ML, Disko R, Dreazen O, Dumon H, Grillo R, Gross U, et al: The past and present role of the Sabin-Feldman dye test in the serodiagnosis of toxoplasmosis. Bull World Health Organ 77: 929-935, 1999.

30. Jiang S, Hua E, Liang M, Liu B and Xie G: A novel immunosensor for detecting toxoplasma gondii-specific IgM based on goldmag nanoparticles and graphene sheets. Colloids Surf B Biointerfaces 101: 481-486, 2013.

31. Laderman EI, Whitworth E, Dumaual E, Jones M, Hudak A, Hogrefe W, Carney J and Groen J: Rapid, sensitive, and specific lateral-flow immunochromatographic point-of-care device for detection of herpes simplex virus type 2-specific immunoglobulin $\mathrm{G}$ antibodies in serum and whole blood. Clin Vaccine Immunol 15: 159-163, 2008.

32. Leruez-Ville M, Vauloup-Fellous C, Couderc S, Parat S, Castel C, Avettand-Fenoel V, Guilleminot T, Grangeot-Keros L, Ville Y, Grabar S and Magny JF: Prospective identification of congenital cytomegalovirus infection in newborns using real-time polymerase chain reaction assays in dried blood spots. Clin Infect Dis 52: 575-581, 2011.

33. Jans H, Liu X, Austin L, Maes G and Huo Q: Dynamic light scattering as a powerful tool for gold nanoparticle bioconjugation and biomolecular binding studies. Anal Chem 81: 9425-9432, 2009.

34. Liu X, Dai Q, Austin L, Coutts J, Knowles G, Zou J, Chen H and Huo Q: A one-step homogeneous immunoassay for cancer biomarker detection using gold nanoparticle probes coupled with dynamic light scattering. J Am Chem Soc 130: 2780-2782, 2008.

35. Safenkova I, Zherdev A and Dzantiev B: Factors influencing the detection limit of the lateral-flow sandwich immunoassay: a case study with potato virus X. Anal Bioanal Chem 403: 1595-1605, 2012 .

36. Thobhani S, Attree S, Boyd R, Kumarswami N, Noble J, Szymanski M and Porter RA: Bioconjugation and characterisation of gold colloid-labelled proteins. J Immunol Methods 356: 60-69, 2010. 